\title{
Kinetics of Austenite Grain Growth During a Continuous Heating of a Niobium Microalloyed Steel
}

\author{
D. San Martín, F. G. Caballero, C. Capdevila, \\ and C. García de Andrés* \\ Solid-Solid Phase Transformations Group (GITFES), Department of Physical Metallurgy, Centro \\ Nacional de Investigaciones Metalúrgicas (CENIM), Consejo Superior de Investigaciones \\ Científicas (CSIC) , Av. Gregorio del Amo 8, 28040, Madrid, Spain. \\ *Corresponding author: cgda@cenim.csic.es. Fax number: +34 915347425 \\ David San Martín: dsm@cenim.csic.es; F.G. Caballero: fgc@cenim.csic.es; \\ C. Capdevila: ccm@cenim.csic.es
}

Keywords: Grain growth, microalloyed steel, continuous heating.

\begin{abstract}
Grain growth is a thermally activated process in which the average grain size increases as temperature and time increases. The driving force for grain growth results from the decrease in the free energy associated with the reduction in total grain boundary energy. There are several known factors that influence the migration of grain boundaries such as second phase particles precipitated in the matrix and the solute elements segregated at grain boundaries. The austenite grain boundaries are revealed using the thermal etching method. Carbon extraction replicas were prepared to determine the composition and size of precipitates present in the matrix. In this work, the evolution of the average prior austenite grain size (PAGS) of a low carbon steel microalloyed with niobium is studied as a function of temperature and heating rate. Austenite grains show a twostage growth. It has been found that as heating rate increases, the grain coarsening temperature $\left(T_{G C}\right)$ increases and the grain size at that temperature decreases. $T_{G C}$ temperature lies around 40$60^{\circ} \mathrm{C}$ below the temperature for complete dissolution of carbonitrides $\left(T_{\text {DISS }}\right)$.
\end{abstract}

\section{Introduction}

In many ways austenite is the parent of the other microstructures, not only from the viewpoint that the other structures arise from its decomposition, but also that it provides the framework for some of their characteristics. Shape and size of the austenite grain will determine the rates of transformation through points of nucleation and paths for transformation. Thus, due to its major influence on final microstructure and, therefore, on mechanical, electrical, and magnetical properties, the accurate experimental determination and theoretical prediction of the prior austenite grain size (PAGS) of materials becomes of the greatest importance in metallurgical studies [1-3].

The driving force for grain growth results from the decrease in the free energy of the system. The grain boundary area is the main source of energy in the austenitic microstructure; therefore, during this process the system will evolved to reduce its grain boundary area. The larger grains will grow at the expense of the smaller ones. Microalloying elements like vanadium, niobium and titanium have been employed in the past two decades to produce fine precipitation in the matrix. The austenite grain boundaries and dislocations are pinned by these precipitates, inhibiting their movement during the thermomechanical processing of steels [4]. The influence of these elements is shown by the way they delay the grain growth process and also the phase transformations, during subsequent cooling, affecting $A r_{3}$ temperature [5]. Therefore, their influence leads to fine-grained microstructures with improved mechanical properties. 
The present article describes the austenite grain growth during a continuous heating at different rates in a niobium microalloyed steel. The thermal etching method [6] is used to reveal the austenite grain boundaries. Carbon extraction replicas were prepared to determine the composition and size of precipitates present in the matrix.

\section{Materials and experimental procedure}

Materials. A low-carbon niobium microalloyed steel has been studied. Its Chemical composition is listed in Table 1.

Table 1 Chemical composition [wt. \%]

\begin{tabular}{cccccccccccc}
\hline $\mathrm{C}$ & $\mathrm{Mn}$ & $\mathrm{Si}$ & $\mathrm{S}$ & $\mathrm{P}$ & $\mathrm{Nb}$ & $\mathrm{Cu}$ & $\mathrm{Cr}$ & $\mathrm{Ni}$ & $\mathrm{Mo}$ & $\mathrm{Al}$ & $\mathrm{N}$ \\
\hline 0.11 & 1.47 & 0.27 & 0.013 & 0.015 & 0.031 & 0.011 & 0.03 & 0.03 & 0.006 & 0.039 & 0.0051 \\
\hline
\end{tabular}

Heat Treatment. Thermal etching method. Cylindrical samples $3 \mathrm{~mm}$ in diameter and $12 \mathrm{~mm}$ in length were used to reveal grain boundaries by the thermal etching method. For this purpose, a surface $2 \mathrm{~mm}$ in width was generated along the longitudinal axis of samples by polishing and finishing with $1 \mu \mathrm{m}$ diamond paste. Later on, samples were heat-treated in a very low thermal inertia radiation furnace of an Adamel Lhomargy DT1000 dilatometer [6]. Specimens were austenitized in vacuum $(>1 \mathrm{~Pa})$ at different heating rates $(H R)$ and at temperatures ranging from $910^{\circ} \mathrm{C}$ to $1250^{\circ} \mathrm{C}(\mathrm{T} \gamma)$. Subsequently samples were cool down to room temperature at $1^{\circ} \mathrm{C} / \mathrm{s}$. Table 2 lists the heating rates and austenization temperatures tested

Table 2 Heating rates and austenitization temperatures

\begin{tabular}{cc}
\hline $\mathrm{HR}\left[{ }^{\circ} \mathrm{C} / \mathrm{s}\right]$ & $\mathrm{T} \gamma\left[{ }^{\circ} \mathrm{C}\right]$ \\
\hline $0.05,0.5,5$ & $910,950,1000,1050,1100,1150,1200,1250$ \\
\hline
\end{tabular}

These samples do not require metallographic preparation after heat treatment; the prior austenite grain boundaries are revealed without chemical etching.

Prior austenite grain size (PAGS). The average PAGS was measured using an image analyser. Pictures were acquired and processed in order to generate a binary image in which prior austenite grain boundaries were shown in black. The average area of austenite grains in $2-D, \bar{A}$, was obtained from this binary images. In this work, the PAGS will be considered as the average diameter of a two-dimensional grain with an area equivalent to $\bar{A}$ [7],

$$
\bar{D}=\sqrt{4 \bar{A} / \pi}
$$

Two-step extraction replica method. A two-step extraction carbon replica method has been used to examine and identify precipitates present in the austenite grain boundaries. In a first stage, triacetylcellulose thin films, which can be easily pasted onto the specimen surface with methyl acetate and then stripped off, are obtained. Thus, the time required for producing the first-step replica is merely a few minutes. The second step consists in evaporation of carbon onto the plastic film in a high vacuum environment. Full details on this method can be found somewhere else [8$11]$.

Carbon replicas obtained using this method where examine using a Jeol Jem 2010 TEM with an energy dispersive spectroscopic (EDS) analyser Oxford Inca. 


\section{Results and discussion}

Fig.1 shows the evolution of the prior austenite grain size (PAGS) during a continuous heating at $0.05,0.5$ and $5^{\circ} \mathrm{C} / \mathrm{s}$. Fig. 2 shows the austenitic microstructure formed after heating up to three different temperatures at a rate of $5^{\circ} \mathrm{C} / \mathrm{s}$.

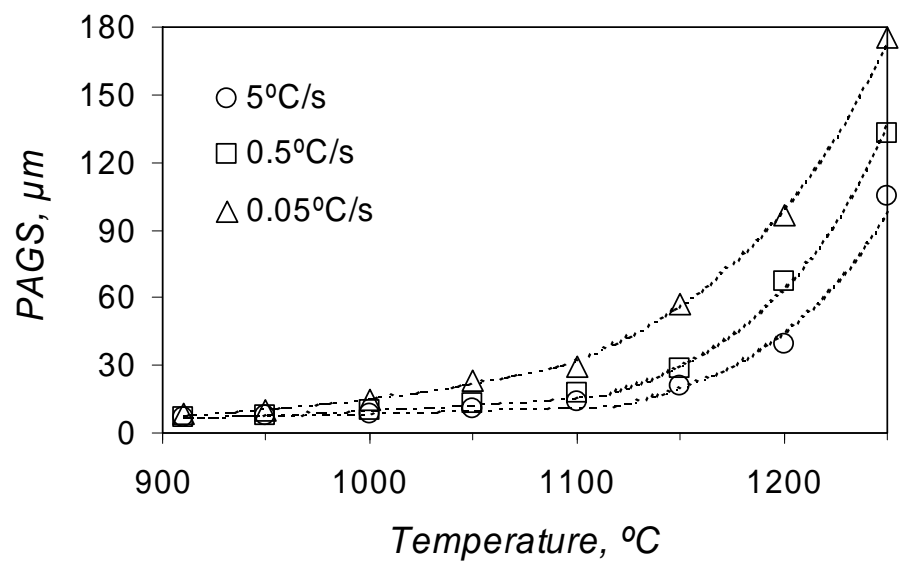

Fig.1 Evolution of the prior austenite grain size (PAGS) for three different heating rates.
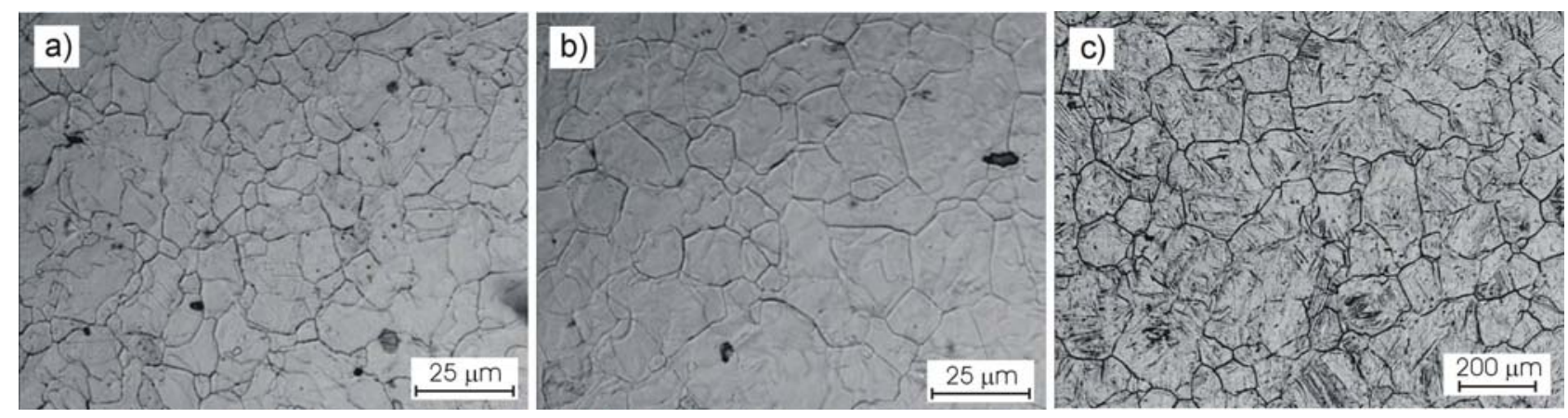

Fig.2 Austenitic microstructure obtained after heating at $5^{\circ} \mathrm{C} / \mathrm{s}$; a) $1050^{\circ} \mathrm{C}$, b) $1150^{\circ} \mathrm{C}$ and c) $1250^{\circ} \mathrm{C}$

It is well known that in plain carbon steels the PAGS increases continuously and exponentially with temperature [12]. However, in microalloyed steels is usual to observe two-step grain growth $[12,13]$. In the niobium microalloyed steel studied in the present work this two-step growth is found during a continuous heating. Until temperatures around $1100^{\circ} \mathrm{C}$ the $P A G S$ evolves very slowly, while above this critical temperature increases very rapidly. The sluggish grain growth in the first step is associated with the existence of second phase particles that pin the grain boundaries, inhibiting their movement.

Carbon replicas showed that niobium carbonitrides were precipitated in the matrix (Fig. 3). The average radius for carbonitrides measured from carbon replicas just above $A c_{3}$ temperature was $r_{0} \sim 10^{-2} \mu \mathrm{m}$. ' $\mathrm{Cu}$ ' peaks in the EDS spectrum corresponds to the copper mesh that supports the replica. Zener [14] proposed the first model to evaluate the influence of particle inhibiting effect on grain boundary motion. This model balances the force for grain growth that arises from the decrease in grain boundary area per unit volume, against the pinning force caused by second phase 
particles precipitated in the matrix. From this relation the following general equation can be obtained,

$\bar{D}_{\text {crit }}=\beta(r / f)$.

Where $\bar{D}_{\text {crit }}$ is the average critical PAGS of the microstructure in the presence of a volume fraction of second phase particles, $f$, that have a mean radius, $r$. The value of $\beta$ depends on factors such as the geometry of particles and austenite grains, or coherency between particle and matrix.
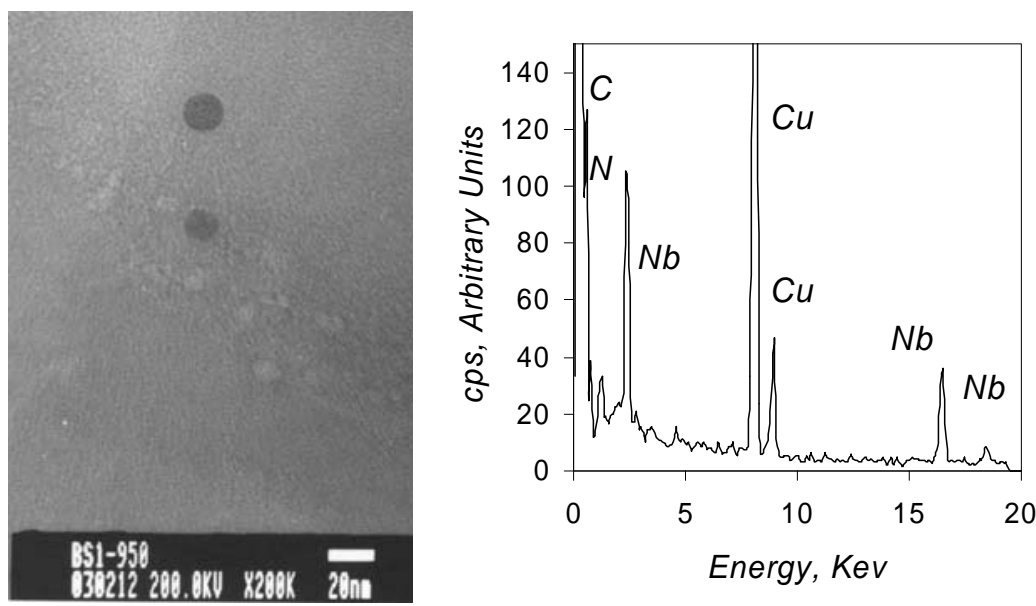

Fig. 3. Niobium carbonitride precipitated in the matrix.

During heating dissolution of particles takes place. This process has two effects: a direct effect in reducing the volume fraction of particles, and an indirect effect of increasing their rate of ripening (increasing the size of particles) by providing a higher solute level in solid solution. According to Eq. 2, both effects contribute to the increase of the critical grain size $\bar{D}_{\text {crit }}$ during reheating.

According to the theory by Lifshitz and Slyozov [15] the variation of the radius of niobium carbonitride will take place at a rate proportional to the diffusivity of niobium in austenite and to the amount of niobium in solid solution in equilibrium with austenite, [Nb]. The diffusivity of niobium is much lower than the diffusivity of carbon or nitrogen in austenite; this is why, niobium volume diffusion is supposed to be the rate controlling process during ripening of carbonitrides. The amount of niobium in solid solution can be obtained from the solubility product of niobium carbonitrides, which is given by the following equation [16],

$$
\log [N b][C+(12 / 14) N]=2.26-(6770 / T) .
$$

Where $C$ and $N$, are carbon and nitrogen in solid solution respectively, and $T$ is temperature in K. $C_{e q}=C+(12 / 14) N$ is the carbon equivalent. Introducing composition in Eq. 3, a temperature of complete dissolution of carbonitrides ( $T_{D I S S}$ ) of $1164^{\circ} \mathrm{C}$ is obtained, very similar to that given by MTDATA software [17] $\left(\sim 1150^{\circ} \mathrm{C}\right)$, assuming that in the initial microstructure all $\mathrm{Nb}$ was present in the form of carbonitrides.

The grain coarsening temperature $\left(T_{G C}\right)$ is defined as the temperature at which abnormal or discontinuous growth begins. As it was mentioned above (Fig. 1) in the studied steel the austenite growth occurs in two steps. Each step, one below around $1100^{\circ} \mathrm{C}$ (first four points, $910-1050^{\circ} \mathrm{C}$ ) and one above this temperature (last three points, $1150-1250^{\circ} \mathrm{C}$ ) has been approximated by an 
exponential function of temperature. As a first approach, it has been considered that $T_{G C}$ is that at which the approximated functions corresponding to each step intersect. Results obtained are shown in Table 3.

Table 3. Grain coarsening temperature $\left(T_{G C}\right)$ and corresponding PAGS.

\begin{tabular}{ccc}
\hline $\mathrm{HR}\left[{ }^{\circ} \mathrm{C} / \mathrm{s}\right]$ & $\mathrm{T}_{\mathrm{GC}}\left[{ }^{\circ} \mathrm{C}\right]$ & $\mathrm{PAGS}[\mu \mathrm{m}]$ \\
\hline 0.05 & 1095 & 30 \\
0.5 & 1111 & 17 \\
5 & 1120 & 12 \\
\hline
\end{tabular}

From Table 3 several conclusions can be drawn. First, $T_{G C}$ lies around $40-60^{\circ} \mathrm{C}$ below $T_{D I S S}$. Grain boundary unpinning requires that the particles dissolve and grow only to an extent at which the pinning force falls below a critical value and this happens well below $T_{\text {DISS. This result is in }}$ agreement with the experimental work of Palmiere et al [16], Cuddy el al [13] and Gladman et al [18]. Second, the higher the heating rate, the higher the $T_{G C}$ is. This is due to the fact that with high heating rates equilibrium conditions are not attained. Non-equilibrium leads to less niobium in solid solution and therefore, a decrease in the rate of dissolution and coarsening of precipitates. And finally, the higher the heating rate, the lower the PAGS is at which grain coarsening starts.

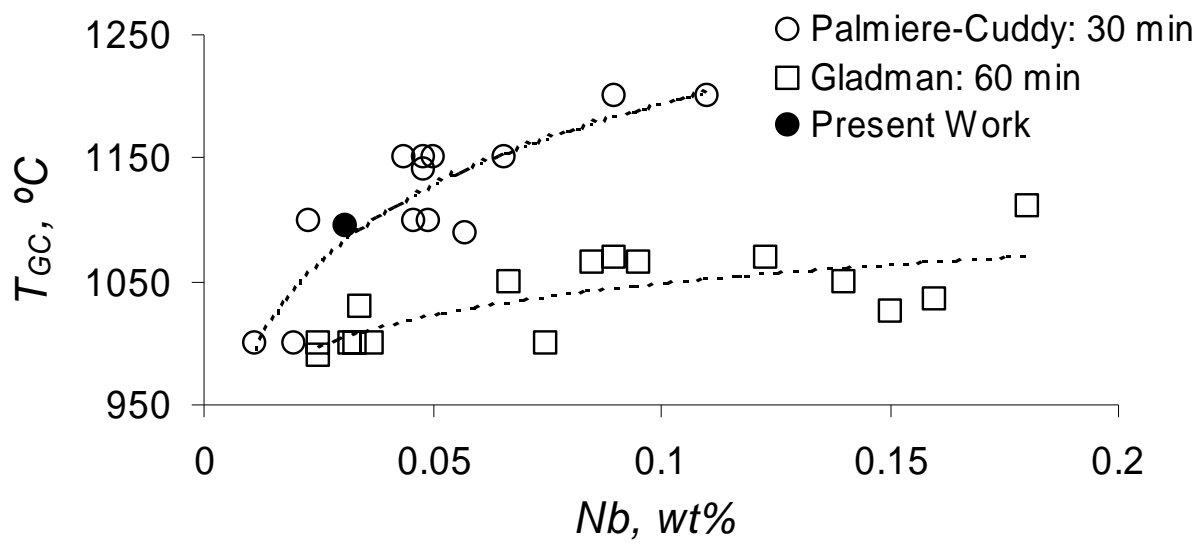

Fig. 5. Evolution of the grain coarsening temperature, $T_{G C}$, with niobium content. Black point refers to present work heating at $0.05^{\circ} \mathrm{C} / \mathrm{s}$.

Fig. 5, represents experimental $T_{G C}$ measured by Palmiere et al [13], Cuddy et al [13], and Gladman et al [18] against niobium content. Data corresponding to steels from the work of Palmiere et al and Cuddy et al have similar amount of $C_{e q}=0.07-0.09$ and were obtained after heating for 30 minutes at the corresponding austenitizing temperature. By contrast, steels from the work of Gladman et al have a carbon equivalent $C_{e q}=0.11-0.21$. From this figure, it seems to be a tendency to have a higher $T_{G C}$ the higher the $N b$ content in the steel and as long as sufficient $C_{e q}$ content is available in the steel to form more carbonitrides. The black circle refers to the present work for a heating rate of $0.05^{\circ} \mathrm{C} / \mathrm{s}$.

The discrepancy observed in Fig. 5 between data by Gladman et al and the other authors is probably due to the difference in the size of carbonitrides. Gladman used a longer austenitization time, thus precipitates would have more time to coarsen during isothermal treatment. Also, the different way in which Gladman et al induced precipitation of carbonitrides would have led to a bigger initial mean size of precipitates. According to Eq. 2, this microstructure would have conducted to a higher $\bar{D}_{\text {crit }}$ and, therefore, unpinning by particles would have occurred at a lower temperature (as shown in Fig. 5) for the same composition and temperature. In the same sense, our 
result confirms that, in the present steel, most of the carbonitrides precipitated in the matrix at the onset of grain growth are around the same size (10nm, Fig. 3) compared with those of the work by Cuddy et al. and Palmiere et al. (5-10nm)

\section{Conclusions}

The niobium microalloyed steel studied shows a two-stage grain growth during a continuous heating. For low temperatures the prior austenite grain size (PAGS) evolves very slowly due to the existence of niobium carbonitrides precipitated in the matrix, while at higher temperatures PAGS increases very rapidly. The grain coarsening temperature $\left(T_{G C}\right)$ has been obtained. It has been found that as heating rate increases, $T_{G C}$ temperature increases and the grain size at that temperature decreases. $T_{G C}$ temperature lies around $40-60^{\circ} \mathrm{C}$ below the temperature for complete dissolution of carbonitrides $\left(T_{D I S S}\right)$.

\section{Acknowledgement}

The authors acknowledge financial support from Spanish Ministerio de Ciencia y Tecnología (Project PETRI PTR 1995-0667-OP). F.G. Caballero would like to thank Spanish Ministerio de Ciencia y Tecnología for the financial support in the form of a Ramón y Cajal contract (Programa RyC 2002).

\section{References}

[1] H. Ohtani, F. Terasaki, T. Kunitake: Trans. ISIJ, Vol. 12, 1972, p. 118.

[2] N. J. Petch: J. of the ISIJ, Vol. 174, 1953, p. 25.

[3] A. Grange: Trans. ASM, Vol. 59, 1966, p. 26.

[4] N.T. Baker: Future Developments of Metals and Ceramics (Institute of Materials, edited by J.A. Charles, G.W. Greenwood and G.C. Smith, London, 1992), p. 75.

[5] P.K. Amin and F.B. Pickering: Thermomechanical processing of microalloyed austenite, (TMS-AIME, Warrendale, PA, 1982), p. 1.

[6] C. García de Andrés, M. J. Bartolomé, C. Capdevila, D. San Martín, F. G. Caballero, V. López: Mater. Charact., Vol. 46, 2001, p. 389.

[7] ASTM E 112-96: Standard Test Methods for Determining Average Grain Size, p. 227

[8] G. R. Booker, J. Norbury: British J. of Appl. Phys., Vol. 8, 1957, pp. 109.

[9] C. P. Scott, D. Chaleix, P. Barges, V. Rebischung: Scripta Mater., Vol. 47, 2002, p. 845.

[10] S. G. Hong, H. J. Jun, K. B. Kang, C. G. Park: Scripta Mater., Vol. 48, 2003, p. 1201.

[11] A. Fukami: Jeol News, July, 1967, p. 5.

[12] R. Coladas, J. Masounave, G. Guérin, And J.-P. Bailón, Met. Sci., November, 1977, p. 509

[13] L.J. Cuddy and J. C. Raley: Metall. Trans. A, Vol. 14, 1983, p. 1989.

[14] C. Zener, quoted by C. S. Smith: Trans. AIME, Vol. 175, 1948, p. 47.

[15] I.M. Lifshitz and V.V. Slyozov: J. of Phys. Chem. Of Solids, Vol. 19, 1961, p.35

[16] E.J. Palmiere, C.I. Garcia and A.J. DeArdo: Metall and Mater. Trans. A, Vol. 25, 1994, p. 277.

[17] H. Davies: MTDATA (National Physical Laboratory, Teddington, UK, 2003).

[18] T. Gladman and F. B. Pickering: J. of the ISI, Vol. 205, 1967, p. 653. 